\title{
Declining pattern of bilirubin in the first and second six hours of intensive versus double phototherapy in neonatal jaundice
}

\author{
Peymaneh Alizadeh Taheri ${ }^{1}$, Negar Sajjadian ${ }^{2 *}$, Mahdi Asadi ${ }^{3}$ and Peyman Salamati ${ }^{4}$ \\ ${ }^{1}$ Associate Professor of Pediatrics, Neonatologist, Bahrami Hospital, Tehran University of Medical Sciences, Tehran, Iran \\ ${ }^{2}$ Associate Professor of Pediatrics, Neonatologist, Shariati Hospital, Tehran University of Medical Sciences, Tehran, Iran \\ ${ }^{3}$ Pediatrician, Bahrami Hospital, Tehran University of Medical Sciences, Tehran, Iran. \\ ${ }^{4}$ Associate Professor of Community Medicine, Bahrami Hospital, Tehran University of Medical Sciences, Tehran, Iran
}

\begin{abstract}
Background: Although phototherapy has been used in clinical practice for 50 years, there is still much debate about how the most efficacious phototherapy application can be provided.

Objective: This study aimed to define the most effective hours of declining serum bilirubin in two types of phototherapy (double versus intensive phototherapy) in treatment of severe hyperbilirubinemia of neonates.

Materials and methods: A total of 100 healthy full-term neonates with no hemolytic hyperbilirubinemia (total serum bilirubin between 20 to $25 \mathrm{mg} / \mathrm{dl}$ ) were compared in a historically controlled study. The first group received double phototherapy (DP) (8 lamps) and the second group received intensive phototherapy (IP) (12 lamps).

Results: The mean serum bilirubin decline in IP group was statistically significant in comparison with DP group in the first 6 hours of phototherapy (4.65 $\pm 2.02 \mathrm{mg} /$ $\mathrm{d} l$ versus $3.59 \pm 1.86 \mathrm{mg} / \mathrm{dl}, \mathrm{P}=0.008)$. The mean serum bilirubin decline was not statistically significant $(\mathrm{P}=0.277)$ in the second 6 hours of phototherapy between two groups.

Conclusion: This study showed IP declined bilirubin level more than DP statistically in the first 6hoursof phototherapy. As there was no difference between DP and IP in the rate of bilirubin decline in the second 6 hours of phototherapy, DP can be used instead of IP if total bilirubin is high but under exchange transfusion level in the second 6 hours of phototherapy.
\end{abstract}

\section{Background}

Neonatal hyperbilirubinemia is one of the most common diseases worldwide and can be treated effectively by phototherapy $[1,2]$. Although it is usually benign in term and preterm neonates [3], severe hyperbilirubinemia is a medical emergency because bilirubin is neurotoxic substance [4] that can cause neurologic defects [5]. Management of hyperbilirubinemia in neonates is still a critical issue. For several decades phototherapy has been known as a standard therapy for neonatal hyperbilirubinemia [6]. Some variables like wave length of light, energy output or irradiance, exposed surface area to the light, the distance between the body and the source of radiation may influence the efficacy of phototherapy [7]. Accordingly, several studies have been done to compare the efficacy of different modes of phototherapy [9].

The aim of this study was to compare the declining pattern of serum bilirubin in the first 6 hours and 12 hours after Intensive phototherapy (IP) versus double phototherapy (DP) in severe neonatal hyperbilirubinemia.

\section{Materials and methods}

This is a historically controlled study conducted in Neonatal ward of Bahrami Children Hospital (Tehran University of Medical Sciences),
Tehran, Iran, between January 2012 to January 2013. The study group consisted of neonates admitted to our neonatal ward to be treated with IP during the study period. These neonates were compared with a historical control group who had been admitted between January 2011 to January 2012 and treated with conventional DP.

Infants who met the following inclusion criteria were assessed: healthy term newborns with birth weight equal to or more than 2500 gr, normal hemoglobin and hematocrit, normal reticulocyte count and total serum bilirubin level of 20-25 mg/dl. Exclusion criteria included any congenital malformations or infections, evidence of hemolysis or blood group incompatibility, history of exchange transfusion and presence of acidosis, hypoglycemia, hypoalbuminemia, sepsis and

Correspondence to: Negar Sajjadian, Associate Professor of Pediatrics, Neonatologist, Shariati Hospital, Tehran University of Medical Sciences, Tehran, Iran, Tel: +98 218490254; Fax: + 9821 88633039; E-mail: nsajjadian@yahoo.com

Key words: double phototherapy, intensive phototherapy, neonatal hyperbilirubinemia

Received: August 08, 2016; Accepted: August 23, 2016; Published: August 25 2016 


\section{G6PD deficiency.}

One thousand fifty five icteric newborns had the mentioned criteria. Of these, 508 subjects were treated with IP and 547 with DP. According to $\alpha=0.05, \mathrm{Z} 1-\alpha / 2=1.96$, power $=80 \%, \mathrm{Z} 1-\beta=0.8, \mathrm{~S} 1$ $=8.5, \mathrm{~S} 2=14.7, \mu 1=31.2, \mu 2=38.98,38$ cases were selected from each group. In order to increase the power of the study, the number of 50 patients was considered in each group.

All infantsin DP group were in bassinets and two single phototherapy (4 lamps) devices were used: one was placed with $25 \mathrm{~cm}$ distance from the bed above the bassinet and the other was placed in line with its length with oblique angle (35 $\mathrm{cm}$ distance from the bed). In IP group, two phototherapy sets, each consisted of 6 phototherapy lamps, were used. One set was placed above and the other one was placed below the infant with $25 \mathrm{~cm}$ distance from the bed. All fluorescent lamps were made by Royal Philips Electrics, Inc (Amsterdam), the Netherlands, with $20 \mathrm{w}$ powers.

The newborns in both groups had eye patches and disposable diapers folded to allow maximum skin exposure to phototherapy. Phototherapy was administered continuously except for minor procedures such as feeding and taking blood sampling.

Total and direct serum bilirubin levels were measured at admission, 6 and 12 hours after beginning of phototherapy. Bilirubin was measured by the conventional indirect diazo method.

The study protocol was approved by research and ethics committee of Tehran University of Medical Sciences. Consent forms were given to the parents and gathered after filling.

Statistical analysis was done by using SPSS software for Windows, version 21.0 (SPSS Inc., Chicago, IL,USA). Independent sample T Test was used to compare quantitative data and the normality of continuous data was checked by Kolmogorov-Smirnov. The Asymp. Sig. (2-tailed) number was calculated $0.628(>0.05)$ that showed normality of continuous data. Statistical significance was considered as $\mathrm{P}<0.05$.

\section{Results}

A total of 100 new born entered the study (50 patients in each group). The patients' characteristics are presented in Table 1. There was no significant difference between patients' sex ratio, birth weight, postnatal age, serum bilirubin level, hematocrit and haemoglobin. Comparison of total serum bilirubin before phototherapy in intensive and double groups showed no significant differences. Phototherapy, either intensive or double, was effective in decreasing bilirubin level but the rate of bilirubin decline was more significant in intensive group than double group. In our study the overall decline rate of $0.65 \pm 0.25$ $\mathrm{mg} / \mathrm{dl} / \mathrm{h}(2.74 \pm 1.03 \% / \mathrm{h})$ in DP was less than the overall decline rate of $0.78 \pm 0.18 \mathrm{mg} / \mathrm{dl} / \mathrm{h}(3.44 \pm 0.78 \% / \mathrm{h})$ in IP with $\mathrm{p}=0.08$ versus $\mathrm{p}<0.01$ (Table 2).

In spite of significant decline rate of serum bilirubin in intensive

Table 1. Clinical and laboratory data of study groups.

\begin{tabular}{|c|c|c|}
\hline Variable & $\begin{array}{c}\text { Intensive phototherapy } \\
(\mathbf{n}=\mathbf{5 0})\end{array}$ & Double phototherapy $(\mathbf{n = 5 0})$ \\
\hline Male to female ratio & $31 / 19$ & $36 / 14$ \\
\hline Birth weight $(\mathrm{g})$ & $3209.70 \pm 362.03$ & $3189.40 \pm 349.20$ \\
\hline Bilirubin $(\mathrm{mg} / \mathrm{dl})$ & $22.67 \pm 1.91$ & $23.63 \pm 2.16$ \\
\hline Hemoglobin $(\mathrm{mg} / \mathrm{dl})$ & $18.20 \pm 2.11$ & $18.01 \pm 1.82$ \\
\hline Hematocrit & $52.72 \pm 5.27$ & $53.75 \pm 5.32$ \\
\hline Post natal age $(\mathrm{d})$ & $6.30 \pm 3.5$ & $7.12 \pm 3.3$ \\
\hline
\end{tabular}

\begin{tabular}{|c|c|c|c|}
\hline Variable & $\begin{array}{c}\text { Intensive } \\
\text { phototherapy }\end{array}$ & $\begin{array}{c}\text { Double } \\
\text { phototherapy }\end{array}$ & P \\
\hline Mean serum bilirubin (mg/dl) & $22.67 \pm 1.91$ & $23.63 \pm 2.1$ & 0.09 \\
\hline $\begin{array}{c}\text { Decrease of serum bilirubin after } \\
\text { the first 6 hours (mg/dl) }\end{array}$ & $4.65 \pm 2.02$ & $3.59 \pm 1.86$ & 0.008 \\
\hline $\begin{array}{c}\text { Decrease of serum bilirubin after } \\
\text { the second 6 hours (mg/dl) }\end{array}$ & $4.47 \pm 1.86$ & $4.32 \pm 1.79$ & 0.277 \\
\hline $\begin{array}{c}\text { Decrease of serum bilirubin after } \\
\text { 12 hours (mg/dl) }\end{array}$ & $9.36 \pm 2.22$ & $7.86 \pm 3.02$ & 0.008 \\
\hline $\begin{array}{c}\text { Overall decline rate of bilirubin } \\
\text { (mg/dl/h) }\end{array}$ & $0.7 \pm 0.18$ & $0.65 \pm 0.25$ & 0.008 \\
\hline $\begin{array}{c}\text { Overall decline rate of bilirubin } \\
\text { (percent/h) }\end{array}$ & $3.44 \pm 0.78$ & $2.74 \pm 1.03$ & $<0.001$ \\
\hline
\end{tabular}

Table 2. The response of groups to phototherapy (Value are given as mean \pm SD).

group in comparison with double group in the first 6 hours of phototherapy, the decline rate of serum bilirubin in the second 6 hours of phototherapy had no significant difference between the two groups $(\mathrm{P}=0.27)$.

\section{Discussion}

In this study we compared the efficacy of IP and DP for declining rate of serum bilirubin in 6 and 12 hours of therapy. There was a significant difference in the speed of bilirubin decline rate between the two groups. The patients who received IP showed more decline rate of serum bilirubin after 6 hours in comparison with DP. The decline rate of serum bilirubin was statistically significant in the first 6 hours in IP group $(\mathrm{P}=0.008)$ versus the second 6 hours $(\mathrm{P}=0.277)$ in comparison with DP group.

Naderi's study [10] compared the benefits, complications and length of hospitalization between double and triple phototherapy in term new borns with indirect hyperbilirubinemia. He showed triple phototherapy had no particular benefit to double phototherapy and had no significant difference in overall decline rate of serum bilirubin. In this study the third phototherapy set was placed in the line with width of the bassinette, and a $35 \mathrm{~cm}$ distance from the bed that obviously decreased the efficacy of phototherapy (2009).

Zahed Pasha [11] compared the efficacy of single, double and intensive phototherapy for declining of serum bilirubin. In spite of significant decrease of serum bilirubin in 3 types of phototherapy, intensive phototherapy was more effective than single and safer than double phototherapy in reduction of bilirubin. The change of body temperature as a complication phototherapy was significant in DP but not in IP (2006). His findings confirmed our results. [12,13] studies showed that that double phototherapy reduced serum bilirubin concentration more rapidly than single one. Nuntnarumit and Naka confirmed the same results (2002) [4].

Several studies like [14-16] studies have proven the rapid decline of bilirubin by different kinds of IP. In our study the overall bilirubin decline rate of $0.65 \pm 0.25 \mathrm{mg} / \mathrm{dl} / \mathrm{h}(2.74 \pm 1.03 \% / \mathrm{h})$ in DP was less than the overall bilirubin decline rate of $0.78 \pm 0.18 \mathrm{mg} / \mathrm{dl} / \mathrm{h}(3.44 \pm 0.78$ $\% / h$ ) in IP with $\mathrm{p}=0.08$ versus $\mathrm{p}<0.01$.The mean decline rate of bilirubin in IP was also more significant in the first 6 hours of phototherapy than the second 6 hours. There was no significant difference in the mean decline rate of bilirubin between DP and IP in the second 6 hours of phototherapy (Table 2). It seems when the serum bilirubin level is high, it is optimal to reduce it more rapidly in a short time, so IP is the first choice when available. When serum bilirubin falls to lower levels, there is no superiority of IP for decreasing bilirubin in comparison to DP. If IP is not available, DP can also decrease the high bilirubin level effectively. 
There are different overall decline rate of bilirubin $(\mathrm{mg} / \mathrm{dl} / \mathrm{h}$ and $\% / h$ ) between DP and IP in various studies because of different kinds of DP and IP devices, phototherapy lamps and distances from the patients.

Our results show that IP (12 phototherapy lamps divided equally above and below the baby) is more effective than DP ( 8 phototherapy lamps all above the baby) for declining of serum bilirubin level especially in the first 6 hours of phototherapy in apposite to the second 6 hours of phototherapy.

\section{Conclusion}

This study showed IP declined bilirubin level more than DP statistically in the first 6 hours of phototherapy. As there was no difference between DP and IP in the decline rate of bilirubin in the second 6hoursof phototherapy, DP can be used instead of IP if total bilirubin is high but under exchange transfusion level in the second 6hours of phototherapy.

\section{Authorship and contributorship}

Study concept and design: Peymaneh Alizadeh Taheri; Acquisition of data: Mehdi Asadi, Analysis and interpretation of data: Peyman Salamati, Drafting of the manuscript: Negar Sajjadianand Peymaneh Alizadeh Taheri, Critical revision of the manuscript for important intellectual content: Peymaneh Alizadeh Taheri, Statistical analysis: Peyman Salamatiand Mehdi Asadi, Administrative, technical, andmaterial support: Peymaneh Alizadeh Taheri, Study supervision: Peymaneh Alizadeh Taheri

\section{Acknowledgment}

The authors wish to thank the nursing and laboratory staff of Bahrami Children hospital. We also express our gratitude to Research Development Center of Bahrami Children hospital.

\section{Funding information}

We received no financial support and the costs of this research were paid by the researchers.

\section{Competing interest}

The authors declare that they have no competing interests.

\section{References}

1. Muchowski KE (2014) Evaluation and treatment of neonatal hyperbilirubinemia. $A m$ Fam Physician 89: 873-878. [Crossref]

2. Porter ML, Dennis BL (2002) Hyperbilirubinemia in the term newborn. Am Fam Physician 65: 599-606. [Crossref]

3. American Academy of Pediatrics Subcommittee on Hyperbilirubinemia (2004) Management of hyperbilirubinemia in the new born infant 35 or more weeks of gestation. Pediatrics 114: 297-316. [Crossref]

4. Nuntnarumit P, Naka C (2002) Comparison of the effectiveness between the adapteddouble phototherapy versus conventional-single phototherapy. J Med Assoc Thai 85: 1159-1166.

5. Provisional committee for quality improvement and subcommittee on hyperbilirubinemia, American Academy of Pediatrics (1994) Practice parameter: Management of hyperbilirubinemia in the healthy term newborn. Pediatrics 94: 558-565.

6. Dennery PA, Seidman DS, Stevenson DK (2001) Neonatal hyperbilirubinemia. N Engl J Med 344: 581-590. [Crossref]

7. Barrington KJ, Sankaran K. Guidelines for detection, management and prevention of hyperbilirubinemia in term and late preterm new born infants. Canadian Paediatric Society.

8. Fetus and Newborn Committee (2007) Paediatr Child Health 12: 1B-12B.

9. Keren R, Luan X, Friedman S, Saddlemire S, Cnaan A, et al. (2008) A comparison of alternative risk-assessment strategies for predicting significant neonatal hyperbilirubinemia in term and near-term infants. Pediatrics 121: e170-179. [Crossref]

10. Naderi S, Safdarian F, Mazloomi D, Bushehri E, Hamidian R (2009) Efficacy of double and triple phototherapy in term newborns with hyperbilirubinemia: the first clinical trial. Pediatr Neonatol 50: 266-269. [Crossref]

11. Zahedpasha Y, Ahmadpour M, Fuladinejat M, Alizadeh R, Mazlomi A ,et al. (2006) Single and double versus intensive phototherapy in term new borns with severe hyperbilirubinemia. Iran J Pediatr 16: 19-24.

12. Kang JH, Shankaran S (1995) Double phototherapy with high irradiance compared with single phototherapy in neonates with hyperbilirubinemia. Am J Perinatol 12: 178180. [Crossref]

13. Milyana NS, Tjipta GD , Ali M, Azlin E, Lubis BM, et al. (2011) Effectiveness of single and double phototherapy on indirect hyperbilirubinemia in neonates. Paediatr Indones 51: 316-321.

14. Boonyarittipong P, Kriangburapa W, Booranavanich K (2008) Effectiveness of doublesurface intensive phototherapy versus single-surface intensive phototherapy for neonatal hyperbilirubinemia. J Med Asso Thai 91: 50-55.

15. Abd-Ellatif MA, Abd-Ellatif DA (2012) The use of intensive phototherapy in severe neonatal hyperbilirubinemia. J Egypt Soc Parasitol 42: 483-494. [Crossref]

16. TakcÄ S, YiÄŸit S, Bayram G, Korkmaz A, YurdakÃk M (2013) Comparison of intensive light-emitting diode and intensive compact fluorescent phototherapy in nonhemolytic jaundice. Turk J Pediatr 55: 29-34. [Crossref]

Copyright: (C2016 Taheri PZ. This is an open-access article distributed under the terms of the Creative Commons Attribution License, which permits unrestricted use, distribution, and reproduction in any medium, provided the original author and source are credited. 